\title{
Characterization of Kaolin as Nano Material for High Quality Construction
}

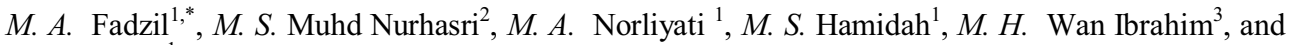 \\ R. Z. Assrul ${ }^{1}$ \\ ${ }^{1}$ Institut of Infrastructure Engineering and Sustainable Management(IIESM), Faculty of Civil \\ Engineering, Universiti Teknologi MARA, 40450 Shah Alam, Selangor, Malaysia \\ ${ }^{2}$ Faculty of Civil Engineering Universiti Teknologi MARA (UiTM), Pulau Pinang, Malaysia \\ ${ }^{3}$ Faculty of Civil and Environmental Engineering, Universiti Tun Hussein Onn Malaysia, 86400 Parit \\ Raja, Johor, Malaysia
}

\begin{abstract}
At the moment utilisation of nano technology in every aspect in human life were growing rapidly. In this research, a new nano material was produce from kaolin clay and compare to OPC in terms of surface analysis, particle sizing and micrograph image on new modification of kaolin clay particles. Kaolin clay was established in two processes which are before and after heat treatment. Apart from that, transformation of kaolin clay to nano material was monitor by using Field Emission Scanning Electron Microscope (FESEM) and new nano materials were formed. Those images were supported by X Ray Diffraction analysis (XRD), X Ray Fluorescence (XRF) and laser particle analyser to see the chemical composition and particle size for all specimens. A combination of rough, smooth and long section can be analysed. From this analysis a new develops nano materials can be achieved and can be utilised especially for construction purposes.
\end{abstract}

\section{Introduction}

Since late 50's, human trying to develop a new material than has a super-size reduction from millimetres to macron based material [1-3]. The idea came to develop from macron to micron started at the early 60's and micron based technology had improved a lot to manufactured small scale gadget or instrument and benefit to human and improved quality of life. Since then, human are trying to improve and enhance technology by inventing less than micro size materials. The idea came from Sobolev to reduce and creating micro to smaller size. From that nano size where introduced to world [3-5].

Kaolin clay or white clay, rich in kaolinite mineral and also classified as layered silicate mineral. Due to endothermic process or dehydroxylation process which involves heat, kaolin particles can easily transform into other shape or particles [6-8]. The reaction of endothermic process will creates metakaolin. In metakaolin formation, the new formed kaolin based product was very reactive. Metakaolin were popular in the ceramic industries and also as construction materials $[9,10]$. Most of the researcher concludes that, metakaolin performs better resistance to water and enhance mechanical properties of concrete [11-13].

\footnotetext{
*Corresponding author: fadiil2013@yahoo.com
} 
Metakaolin in concrete reduces water penetration and alkali silica reaction by acting as filler and increase hydration process. Apart of refining of voids, concrete structures strength of concrete can be increase due to densifying of voids and less voids created [14, 15].

Process of nano forming includes of bottom to up and top to down approach. Selection of that nano process depends on the availability, cost and expertise [16]. Bottom to up approach is consider as expensive but forming a uniform and smaller particles. On contrary, top to down approach provides less cost and easy process of nano forming particles but the size in not uniform [3-5].

In this research, forming of kaolin product as nano materials is not been done intensively. Raw kaolin was produced into metakaolin, nano kaolin and nano clay and technique applied was top to down for nano kaolin and bottom to up for nano clay. There is a quite number of research on nano kaolin but nano kaolin in this research uniquely produced by milling technique. Calcination also involves in transforming the not reactive kaolin based product into reactive kaolin such as metakaolin, nano metakaolin and nano metaclay. From this research a new process is produced from kaolin and the mesopores or microstructures of new nano materials can be discussed.

\section{Methodology}

\subsection{Sample preparation}

In this research all kaolin clay based will be compared to Ordinary Portland Cement (OPC). OPC for this research was supplied by Tasek Cement from Perak, Malaysia. Two types of kaolin clay kaolin clay will be analyse which is nano kaolin and nano clay. Although those kaolin based were the same, but the manufacturing process was different. Before that, kaolin clay was procured by AKI Kaolin (M) Sdn Bhd. in Selangor, Malaysia. Average size given by the manufactured was 10 to 5 micron. To transform kaolin to nano kaolin, high energy milling was the technique applied. Fritsch milling analyser, was the instrument used for transforming kaolin to nano kaolin. To prevent heat generate during milling, ball and jar for was from Zirconia. 15 zirconia balls with $2 \mathrm{~mm}$ diameter were used. Speed of milling was fixed to $400 \mathrm{rpm}$ and duration of milling also fixed to 24 hours. For nano clay, material was procured by Sigma Aldrich (M) Sdn Bhd.

All specimens will undergo secondary treatment. The process of secondary treatment was needed for all kaolin based sample to transform from a single phase structure into amorphous stage. The process of secondary treatment involves heat and also can be called as calcination. Calcination process will be done by using electric furnace. All kaolin sample will underwent calcination process which the temperature and duration was fixed to $700^{\circ} \mathrm{C}$ within 3 hours heated.

To performed analysis of micrograph image of all sample powders, Field Emission Scanning Electron Microscope (FESEM) was implemented. From FESEM analysis, shape and surface texture of all samples can be evaluated. As and addition, chemical composition of all sample powders evaluated by using Horiba Mesa 50 X Ray Fluorescene Analyzer (XRF) and Rigaku X Ray analytical instrument (XRD). Finally Fritsch laser particle analyser was used to analyse particle size of all powder sample. All testing regarding chemical analysis were done at Institute of Science (IOS), UiTM Malaysia. 


\section{Result and discussion}

\subsection{Surface and shape analysis}

From Fig. 1 to 7 shows specimen in powder form for kaolin based material. Kaolin samples will be disgust on the formation before and after milling. Discussion also will include on the behaviour of kaolin samples before and after treatment. All kaolin samples will be compared to OPC in terms of shape and surface texture.

Image of OPC specimen can be seen in Fig. 1. At a glance, rough, irregular, angular shape and texture were the major formation in the molecule of OPC. Most of the rough surface in OPC structure was in amorphous state due to the process of calcination in the cement plant. During calcination silica and alumina combines and creating Tricalcium Silicate $\left(\mathrm{C}_{3} \mathrm{~S}\right)$ which contributes strength, Dicalcium Aluminate $\left(\mathrm{C}_{2} \mathrm{~A}\right)$ which controlling the setting phases during hydration and other minor compound. Angular and irregular texture that can be seen in OPC was the formation $\mathrm{C}_{3} \mathrm{~S}$ and $\mathrm{C}_{2} \mathrm{~A}$. Most of the angularity formation in OPC structure was created by $\mathrm{C}_{3} \mathrm{~S}$ formation. For $\mathrm{C}_{2} \mathrm{~A}$ formation, represent by light whitish line along the outer ring of OPC particles. Rough surface in the OPC structures were created due to incomplete and non-uniform calcination process in cement plant. We can see the formation of tiny layering or mini island texture on the surface of bigger component. Those tiny layering or mini island forms will slowly been deceased during the hydration process which includes water. During hydration tiny spots contain of $\mathrm{C}_{3} \mathrm{~S}$ will react and dilute alumina in the outer ring and creates bonding between other OPC molecules. Although bonding between pastes will enhance strength, due to non-uniformity of OPC particles will creates minor voids between pastes. As a result, surface of newly hydrated product called Calcium Silica Hydrate (CSH) gel were not uniform.

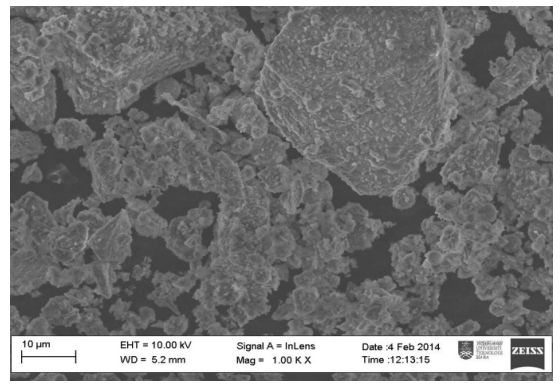

Fig. 1. OPC

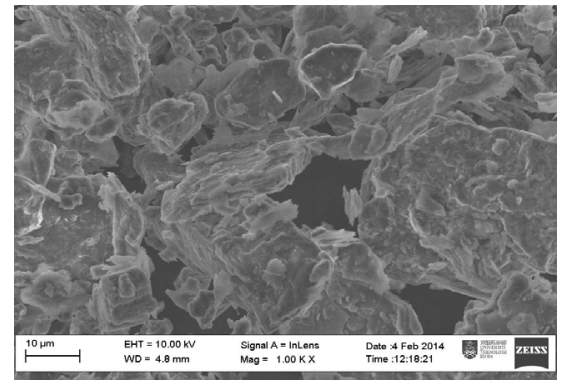

Fig. 2. Kaolin

A kaolin particle was portrayed by Fig. 2. Kaolin also known as white clay regards as high pozzolanic materials due to high content of silica and alumina compare to OPC. However the formation of kaolin particles were a lot different and unique compare to OPC. Shape of kaolin can be described as flaky and platy formation. A smooth surface of kaolin texture can be seen and shows a lot of different compare to OPC texture. The formation of kaolin particles were in layering or flakes system formation and close from one flake to another. As been mentioned earlier, silica and alumina was the major chemical occurs in kaolin. From that we can see that the different between angularities of kaolin flakes are more uniform and compare to sharp edges of OPC. More whitish layer forming the outer ring of kaolin particles represent by alumina shield system. Alumina line can be seen clearly in the flakes system of kaolin particles compare to OPC. During single crystal formation which can be seen in kaolin, alumina line performs a bonding effect from one to other flakes. In addition, alumina shield system creating and forming more surface area 
between kaolin particles and larger voids can be filled up by other kaolin flake. It was clear thus effect of micron based kaolin can be applied as filler in any solid matters such as concrete, soil treatment and water filtering system. In other words, kaolin can also perform as micro filler agent. To support this statement, in terms of packing formation in kaolin less empty voids can be compared to OPC. Due to micro size effect kaolin structure were in tidy and uniform layered component compare to OPC.

Metakaolin micrograph image can be seen from Fig. 3. The formation of metakaolin was from kaolin after calcination. Flaky and platy structure was the main shape texture for metakaolin. Obviously calcination process transforms kaolin into metakaolin that's involving oxidation in the kaolinite structure. Metakaolin surface were smoother compare to kaolin. Formation of metakaolin particles can be seen by bigger flakes were formed and separated from one another. Smooth surface of metakaolin were cause by dilution effect of alumina in metakaolin. Before calcined, alumina bond metakaolin flakes and provides layering system. Tiny spots or mini island of flakes were move apart due to calcination and from that surface of metakaolin were refined. Shape of metakaolin flakes reformed a neat angularity and sharp edges were reduced. Size of metakaolin flakes also are bigger compare to kaolin resulting more space and larger surface area were created. Increase in flakes size due to dilution effect of alumina component during calcination. As been mentioned earlier, alumina can be seen by whitish layer outside the metakaolin flakes. After calcined, whitish layer which represent alumina was obviously seen compare to kaolin.

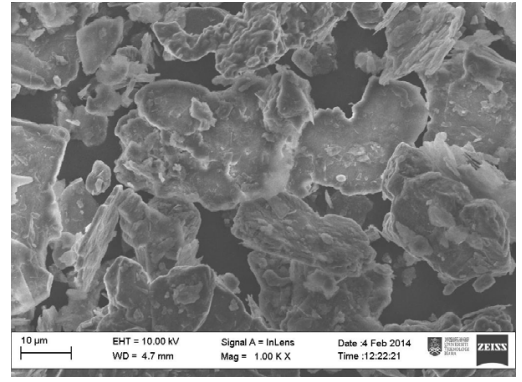

Fig. 3. Metakaolin

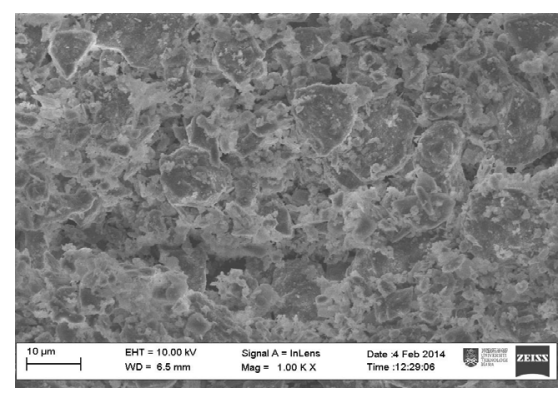

Fig. 4. Nano Kaolin

Nano kaolin was created from kaolin after undergo milling process. Fig. 4 shows the micrograph image of nano kaolin. Milling process proves to reduce the size of kaolin particles. In terms of shape and surface texture, nano kaolin shows a similar texture to kaolin. However due to milling the kaolin flakes has been reduced to nano particles and forming nano kaolin. Average size of nano kaolin recorded was less than $200 \mathrm{~nm}$. As been stated earlier, shape of nano kaolin still maintaining the flaky, platey and tetrahedron formation also known as layering structure. Surface of nano kaolin also in smooth similar to kaolin but increase in the formation of tiny spots or mini island overlay from one another. Smaller particles in the nano kaolin structure resulting in increase in surface area. Since nano kaolin not undergo secondary treatment, alumina layer is not dilute and nano kaolin flakes maintaining the neat tetrahedron or layering flaky formation.

Nano metakaolin were formed from nano kaolin after undergo secondary treatment which is calcination. Fig. 5 portrait image of nano metakaolin. The analysis of shape and surface texture of nano metakaolin is similar to metakaolin only the different was size of particles was smaller. Due to calcination, tetrahedron or layering of flakes were dilute and increase surface area. Again increase in surface area due to the dilution of alumina resulting in fluidising the flakes and unlock the bonding of nano kaolin particles. Calcination process refines and densifies angularity and sharp edges of nano metakaolin flakes and form a 
uniform nano metakaolin structure. Whitish layer represent alumina, can be seen forming at the outer ring of nano metakaolin flakes. Surface of nano metakaolin were smoother compare to metakaolin due to uniform and incomplete calcination process due to smaller particles compare to metakaolin.

Fig. 6 shows micrograph image of nano clay. A different image can be seen through nano clay compare to OPC and kaolin. At a glance, nano clay shape consists of rounded and angular edges. Most of the particles were rounded or ball shape, only size of balls is not equal or uniform. Based on the rounded shape, nano clay can perform a ball bearing effect such as fly ash and silica fume. In addition, nano clay particles are freely to move or mobility to move during mixing with other elements and workable. Although in terms of mobility, movement or flow ability of nano clay is not freely like fly ash or silica fume. This occurs due to clay properties in kaolin performs absorption effect. Surface of nano clay can be considered smoother than OPC but not to kaolin and other samples. It seems like ball formation of nano clay particles in rounded shape overlay from one particle to another. In complete fluidity of nano clay due to no secondary treatment causing to the less smooth surface of nano clay. Uniformity of nano clay particles compare to other samples was due to processing stages by using bottom to up approach. Combination of chemical synthesis method during the production of nano clay help to modify the originality of kaolin particles from flakes particles into rounded or ball flocking formation structure.

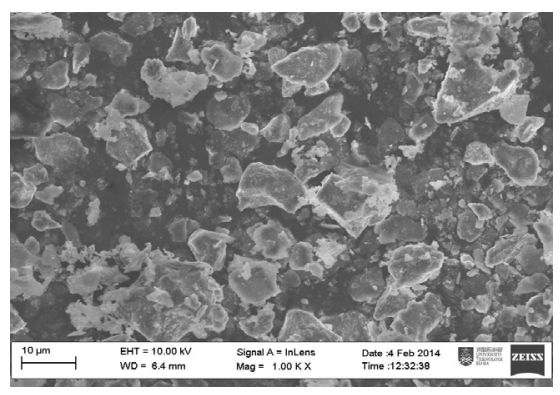

Fig. 5. Nano Metakaolin

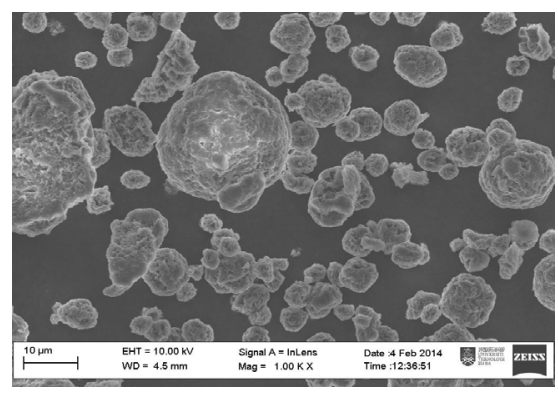

Fig. 6. Nano Clay

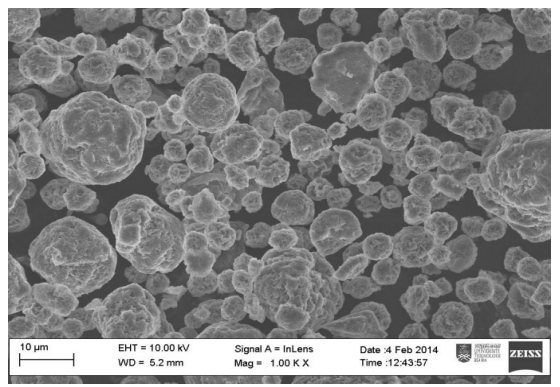

Fig.7. Nano Metaclay

Nano metaclay was created by secondary treatment which involves calcination of nano clay. Fig. 7 shows micrograph image of nano metaclay. Due to calcination, alumina content of nano clay fluidise thus creating dehydrolixation process and causing ball flocking formation. Apart from that, structure of nano clay tends to separate from one to another and smaller ball formation was created. From this situation, more surface area was created and can perform a good filler agent. Fluidise effect of alumina dilution can be seen clearly by whitish line colour outside the outer ring of nano metaclay. Those alumina layer were not seen in nano clay image and from that an obvious different can be seen before and after 
calcine. Smoother surface of nano metaclay also can be compare to nano clay due to fluidise effect. Smaller particles of nano metaclay were created after calcination and resulting in increase in surface area. In conclusion, calcination proves to change the ball flocking formation of nano metaclay into ultra size and smoother surface compare to nano clay.

\subsection{Chemical composition}

Table 1 shows the chemical composition of OPC, kaolin, metakolin, nano kaolin, nano metakaolin, nano clay and nano metaclay. The chemical composition were detected by using $\mathrm{X}$-Raf Fluorenscence (XRF) technique. It can be seen that the content of $\mathrm{SiO}_{2}$ for nano metakaolin was the highest as compared to that of OPC and other specimen. Almost $90 \%$ of silica is recorded in nano metakaolin thus confirmed the potential of strength increment when blending with OPC. The second goes to metakaolin around $75 \%$, nano metaclay less than $70 \%$ and OPC records the lowest content of $\mathrm{SiO}_{2}$ which less than $15 \%$. It can be seen that after treatment from kaolin into metakaolin, nano metakaolin and nano metaclay, a slight increament of silica content were produced. It is believe due to liquidation of tetahedron structure from heat were the factor contributed to this phenomena. For $\mathrm{Al}_{2} \mathrm{O}_{3}$, nano metakaolin also record was the highest as compared to the other which is about $19 \%$. Most of kaolin specimen records higher alumina with respect to OPC. Although transformation of kaolin into other specimen which includes secondary heat treatment, only a slight increament of alumina can be seen for all specimen. The alumina oxide will accelerate the hydration process and setting time. The content of $\mathrm{CaO}$ for nano metakaolin is very minimum which less than $1 \%$ which will reduce the formation of calcium hydroxide in cement paste during hydration. As a conclusion, nano metakaolin can be classified as a very reactive pozzolannic materials because the high content of $\mathrm{SiO}_{2}$ and $\mathrm{Al}_{2} \mathrm{O}_{3}$.

Table 1. Chemical composition of kaolin clay specimen

\begin{tabular}{c|c|c|c|c|c|c|c}
\hline \multirow{2}{*}{ Chemical } & \multicolumn{7}{|c}{ Mass Percentage (\%) } \\
\cline { 2 - 8 } & OPC & Kaolin & Metakaolin & $\begin{array}{c}\text { Nano } \\
\text { Kaolin }\end{array}$ & $\begin{array}{c}\text { Nano } \\
\text { Metakaolin }\end{array}$ & $\begin{array}{c}\text { Nano } \\
\text { Clay }\end{array}$ & $\begin{array}{c}\text { Nanao } \\
\text { Metaclay }\end{array}$ \\
\hline $\mathrm{SiO}_{2}$ & 11.6 & 73.3 & 74.3 & 87.7 & 89.6 & 63.9 & 65.9 \\
\hline $\mathrm{Al}_{2} \mathrm{O}_{3}$ & 2.2 & 14.5 & 17.2 & 17.9 & 18.9 & 14.0 & 15.1 \\
\hline $\mathrm{CaO}$ & 75.17 & 0.058 & 2.4 & 3.33 & 0.43 & 4.8 & 4.3 \\
\hline $\mathrm{TiO}_{2}$ & 0.4 & 1.38 & 1.45 & 1.65 & 1.82 & 1.01 & 0.9 \\
\hline $\mathrm{Fe}_{2} \mathrm{O}_{3}$ & 5.38 & 1.99 & 1.81 & 2.2 & 2.0 & 13.41 & 11.4 \\
\hline $\mathrm{K}_{2} \mathrm{O}$ & 0.43 & 4.86 & 4.64 & 3.41 & 4.55 & 0.27 & 0.24 \\
\hline
\end{tabular}

\subsection{Particle size analysis}

Table 2 and Fig. 8 shows the analysis for particle size for OPC, kaolin, metakaolin, nano kaolin, nano metakaolin, nano clay and nano metaclay respectively. From Table 1.2 we can see huge transformation from micron based into nano particles can be produced. Kaolin and OPC considered as micron based materials have a specific surface area less than 20000 $\mathrm{m}^{2} / \mathrm{kg}$. After calcination of kaolin, kaolin changed to metakaolin and the surface area has increased almost $30000 \mathrm{~m}^{2} / \mathrm{kg}$. the same pattern is seen for calcination sample which involves nano metakaolin and nano clay. Increase in surface area was recorded and the highest was nano metaclay which records around $170000 \mathrm{~m}^{2} / \mathrm{kg}$. Apart from that, nano 
process which involves milling and chemical also helps to reduce the surface area of kaolin and transform into nano kaolin. Effective size for kaolin also be influence by nano transforming process. From Table 2, size of kaolin can be reduced into smaller particles depends on the transforming process. Huge reduction of nano metakaolin particles was recorded which around $176 \mathrm{~nm}$ as compared to $\mathrm{OPC}$ and kaolin. Eventually for nano metaclay, record the lowest particle size as compared to other sample and size recorded is $146 \mathrm{~nm}$.

Table 2. Particle size of kaolin clay specimen

\begin{tabular}{c|c|c|c|c}
\hline Specimen & $\begin{array}{c}\text { D10 } \\
\text { (effective size) } \\
(\mathbf{n m})\end{array}$ & $\begin{array}{c}\text { D30 } \\
(\mathbf{n m})\end{array}$ & $\begin{array}{c}\text { D60 } \\
\mathbf{( n m})\end{array}$ & $\begin{array}{c}\text { Specific Surface } \\
\text { Area } \\
\left(\mathbf{m}^{\mathbf{2}} / \mathbf{k g}\right)\end{array}$ \\
\hline OPC & 2433 & 6954 & 10972 & 12748 \\
\hline Kaolin & 1612 & 5585 & 13325 & 18231 \\
\hline Metakaolin & 925 & 2106 & 7282 & 27847 \\
\hline Nano kaolin & 419 & 773 & 1704 & 63612 \\
\hline Nano Metakaolin & 176 & 395 & 767 & 140792 \\
\hline Nano clay & 269 & 487 & 556 & 98456 \\
\hline Nano metaclay & 146 & 228 & 315 & 168987 \\
\hline
\end{tabular}

Fig. 8 shows particle size distribution of OPC, kaolin, metakaolin, nano kaolin, nano metakaolin, nano clay and nano metaclay. Nano metakaolin record the highest particles less than $500 \mathrm{~nm}$. For nano metakaolin, almost $85 \%$ records the size less than $500 \mathrm{~nm}$ as compared to other sample. Next highest goes to nano kaolin which the product of milling before secondary treatment. For nano metaclay almost $70 \%$ of particles are less than 500 nm.

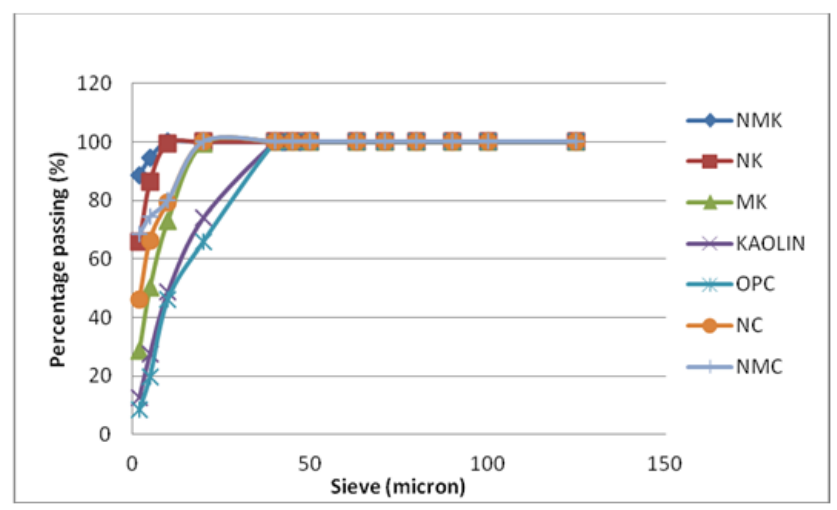

Fig. 8. Particle size distribution of seven (7) samples Of OPC, kaolin, metakaolin, nano kaolin, nano metakaolin, nano clay and nano metaclay

\subsection{XRD analysis}

Fig. 9 and 10 shows the result of XRD analysis of kaolin, metakaolin, nano kaolin, nano clay and nano metaclay. From Fig. 9 a different peak is seen regarding the process of calcination of kaolin specimen. Kaolinite formation of kaolin was reduced as been compared to metakaolin. This happen due to endothermic process during calcination creates a $\mathrm{n}$ amorphous structure of metakaolin. Major content of kaolinite are alumina and alumina and oxidation creates a better formation of alumina and silica. It can be seen by metakaolin where by a lower peak or counts as compared to kaolin. A different peak can be seen by 
nano kaolin and nano metakaolin in Fig. 9. Counts and peak of nano kaolin and nano metakaolin is higher as compared to OPC. Due to nano particles created, causing the peak detecting smaller particles as compared to kaolin. Another different between those specimens, we can see a better or refines peak and noise as compared of kaolin sample and after calcination. Due to oxidation, refining the crystal structures can be seen by a clear noise and more sharp peak by metakaolin and nano metakaolin.

Fig. 10 shows the XRD pattern for nano clay and nano metaclay. Montmorilite is the major compound in nano clay and in montmorilite contains of kaolinite, mica and silica. Due to oxidation, montmorilite peak will be reduced and amorphous structure created. Another examples can be seen on the formation of amorphous structure is the peak of nano metaclay is smoother as compared to nano clay.

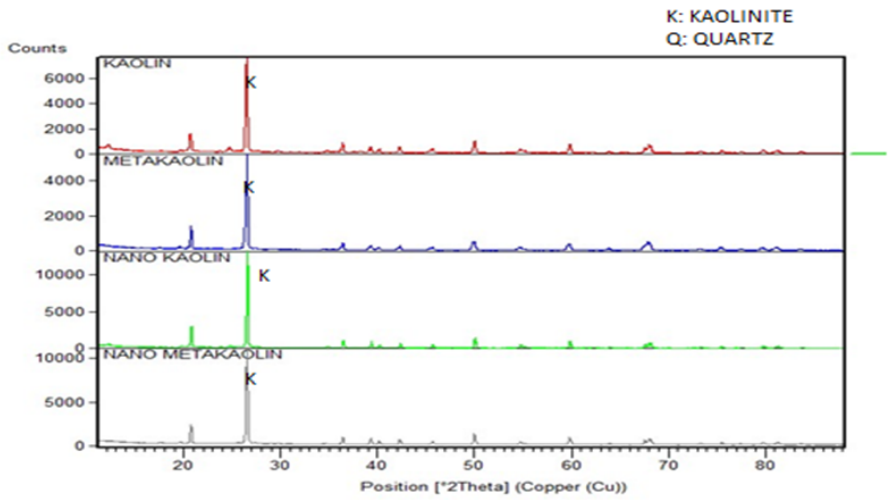

Fig. 9. XRD for kaolin,metakaolin, nano kaolin and nano metakaolin

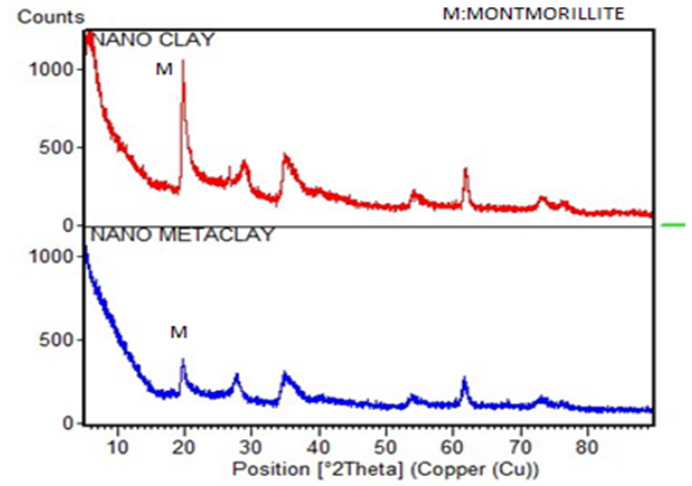

Fig. 10. XRD for nano clay and nano metaclay

\section{Conclusion}

From this research conclusions are drawn as follows:

i) High speed milling can be utilised for processing nano materials. Parameters namely types of milling, types of ball, numbers of ball, speed of rotation and duration of milling are the factors considered.

ii) There are differences in morphology between OPC, kaolin, metakaolin, nano kaolin and nano metakaolin. Calcination process has altered shape and surface texture of kaolin. 


\section{References}

[1] N. Crainic, Nano-composites: A state of the art review, Key Engineering Materials, 230-232, 656-660 (2002)

[2] A.H. Shekaria, Influence of nano particles on durability and mechanical properties of high performance concrete, Procedia Engineering, 14, 3036-3041 (2011)

[3] K. Sobolev, I.F. Roman Hermosillo and L.M. Torres-Martínez, Nanomaterials and nanotechnology for high-performance cement composites, Proceedings of ACI Session on Nanotechnology of Concrete: Recent Developments and Future Perspectives, Denver, (2006)

[4] K. Sobolev, The development of a new method for the proportioning of highperformance concrete mixtures, Cement and Concrete Composites, 26(7), 901-907 (2004)

[5] K. Sobolev and M. Ferrada-Guterrez, How nanotechnology can change the concrete world: Part 1, American Seramic Society Bulletin, 10, 14-17 (2005)

[6] M.S. Morsy, H. Abbas and S.H. Alsayed, Behavior of blended cement mortars containing nano-metakaolin at elevated temperatures, Construction and Building Materials, 35, 900-905 (2012)

[7] L. Dvorkin, A. Bezusyak, N. Lushinikova and Y. Ribakov, Using mathematical modeling for design of self compacting high strength concrete with metakaolin admixture, Construction and Building Materials, 37, 851-864, (2012)

[8] S.M. Mansour, K. Bekkour and I. Messaoudene, Improvement of rheological behaviour of cement pastes by incorporating metakaolin, European J. of Scientific Research, 42(3), 442-452 (2010)

[9] M.A. Megat Johari, S. Khabir and P. Rivard, Influence of supplementary cementitious materials on engineering properties of high strength concrete, Construction and Buildings Materials, 25, 2639 - 2648 (2011)

[10]J. Bai, S. Wild, J.A. Ware and B.B. Sabir, Using neural networks to predict workability of concrete incorporating metakaolin and fly ash, Advances in Engineering Software, 34(11), 663-669 (2003)

[11]B.B. Sabir, S. Wild and J. Bai, Metakaolin and calcined clays as pozzolans for concrete: A review,Cement and Concrete Composites, 23(6), 441-454 (2001)

[12]A.M. Rashad, Metakaolin as cementitious material: History, scours, production and composition - A comprehensive overview, Construction and Building Materials, 41, 303-318 (2013)

[13]A.M. Rashad, Alkali-activated metakaolin: A short guide for civil Engineer - An overview, Construction and Building Materials, 41, 751-765 (2013)

[14]A. Nadeem, S.A. Memon and T.Y. Lo, Mechanical performance, durability, qualitative and quantitative analysis of microstructure of fly ash and metakaolin mortar at elevated temperatures, Construction and Building Materials, 38, 338-347 (2013)

[15]R. Madandoust and S.Y. Mousavi, Fresh and hardened properties of self-compacting concrete containing metakaolin, Construction and Building Materials, 35, 752-760, (2012)

[16]F. Sanchez and K. Sobolev, Nanotechnology in concrete - A review, Construction and Building Materials, 24(11), 2060-2071 (2010) 